\title{
AVALIAÇÃO DO MÉTODO QUÍMICO DE CONTROLE DE PAPUÃ (Brachiaria plantaginea) SOBRE A PRODUTIVIDADE DO MILHO ${ }^{1}$
}

\author{
Leandro Galon², Siumar Pedro Tironi ${ }^{3}$, Evander Alves Ferreira ${ }^{3}$, Ignácio Aspiazu³ ${ }^{3}$ Jesus Juares Oliveira Pinto ${ }^{4}$
}

\section{ABSTRACT \\ CHEMICAL CONTROL EVALUATION OF ALEXANDER GRASS (Brachiaria plantaginea) ON MAIZE (Zea mays) YIELD}

The objective of this study was to evaluate the Brachiaria plantaginea control with pre and post-emergence herbicides and their effects on the hybrid Pioneer 3063 maize yield. The trial was conducted from October 2006 to February 2007, in Capão do Leão, Rio Grande do Sul State, Brazil, by using a complete randomized blocks design, with four replications, under the conventional sowing system. The treatments consisted of the herbicide s-metolachlor $\left(1,620 \mathrm{~g} \mathrm{ha}^{-1}\right)$ and the mixture in tank of atrazine + nicosulfuron $\left(1,250+28 \mathrm{~g} \mathrm{ha}^{-1}\right)$, applied in pre and early post-emergence of the culture, respectively, plus one infested and one weed-free control. The plants of $B$. plantaginea were obtained from the soil seed bank, with average population of 312 plants $\mathrm{m}^{-2}$. The evaluated variables were control of $B$. plantaginea by the herbicides and maize grain yield components, as well as grain yield. Among the herbicides, the one that provided better control of $B$. plantaginea was the mixture atrazine plus nicosulfuron, applied in post-emergence of the crop, maintaining the field free of $B$. plantaginea, from the beginning to the end of the cycle. The herbicide s-metolachlor showed to be an alternative for the initial control of weeds in maize, up to 20 days after emergence. The absence of $B$. plantaginea control caused interference in all grain yield components of maize, being observed up to $98 \%$ of grain yield losses.

KEY-WORDS: Chemical control; herbicide mixtures; weed.

\section{INTRODUÇÃO}

A cultura do milho caracteriza-se por ser uma das mais importantes e tradicionais cultivadas no Brasil, ocupando área de, aproximadamente, 13 milhões de ha, com produtividade média de $3,2 \mathrm{t} \mathrm{ha}^{-1}$ (Conab 2007). No entanto, esta produtividade está muito aquém das obtidas em áreas que adotam maior tecnologia, ou mesmo em campos experimentais. Dentre os muitos fatores responsáveis pela baixa produtivi-

\section{RESUMO}

Objetivou-se, com o trabalho, avaliar o controle de Brachiaria plantaginea, com herbicidas aplicados em pré e pós-emergência, e a influência destes na produtividade do milho híbrido Pioneer 3063. O experimento foi conduzido de outubro de 2006 a fevereiro de 2007, no município de Capão do Leão (RS). Adotou-se o delineamento experimental de blocos casualizados, em sistema de cultivo convencional, com quatro repetições. Os tratamentos foram constituídos pelo herbicida s-metolachlor (1.620 $\left.\mathrm{g} \mathrm{ha}^{-1}\right)$ e pela mistura em tanque de atrazine + nicosulfuron $\left(1.250+28 \mathrm{~g} \mathrm{ha}^{-1}\right)$, aplicados em pré e pós-emergência da cultura do milho, respectivamente, mais testemunha capinada e infestada. A população $B$. plantaginea originou-se do banco de sementes, com população média de 312 plantas $\mathrm{m}^{-2}$. As variáveis avaliadas foram o controle de B. plantaginea e os componentes do rendimento, bem como a produtividade de grãos de milho. O tratamento herbicida que proporcionou melhor controle da planta daninha foi a mistura de atrazine + nicosulfuron, aplicada em pós-emergência da cultura, mantendo-se o controle do início ao fim do ciclo da cultura. O herbicida s-metolachlor mostrou eficiência no controle inicial de plantas daninhas, até os 20 dias após a emergência da cultura. O não controle de $B$. plantaginea causou interferência em todas as variáveis avaliadas, apresentando limitação de produtividade de grãos de até $98 \%$.

PALAVRAS-CHAVE: Controle químico; misturas herbicidas; planta daninha.

dade da cultura do milho, destaca-se a interferência de plantas daninhas. Estima-se que as perdas de rendimento, em função da competição com plantas daninhas, sejam da ordem de 20-30\% (Lorenzi 1994), sendo que, em muitos casos, onde não tenha sido adotado qualquer método de controle, esta redução pode chegar a $85 \%$ (Karam \& Melhorança 2002, Karam \& Cruz 2004), ou mesmo a 100\% (Almeida 1981), em função da espécie, do grau de infestação, das condições edafoclimáticas reinantes no período

1. Trabalho recebido em dez./2008 e aceito para publicação em nov./2010 (nº registro: PAT 5170/ DOI: 10.5216/pat.v40i4.5170).

2. Universidade Federal do Pampa, Departamento de Fitotecnia, Itaqui, RS, Brasil.E-mail: galonleandro@ig.com.br.

3. Universidade Federal de Viçosa, Departamento de Fitotecnia, Viçosa, MG, Brasil.

E-mails: siumar.tironi@gmail.com, evanderalves@yahoo.com.br, aspiazu@gmail.com.

4. Universidade Federal de Pelotas, Departamento de Fitossanidade, Pelotas, RS, Brasil. E-mail: jesuspinto@terra.com.br. 
e do estádio fenológico da cultura em que haja a interferência das plantas daninhas.

A época de início do controle de plantas daninhas tem grande influência no crescimento das plantas e na produtividade de grãos da cultura do milho (Rizzardi et al. 2004). Quando a cultura emite a quinta folha expandida, na presença de plantas infestantes, pode haver influência em algumas características de desenvolvimento e componentes de produção de grãos, como altura da inserção das espigas, comprimento das mesmas, altura das plantas e número de grãos por fileira (Fancelli \& Dourado Neto 2000). A população de plantas e o número de espigas por planta (Zagonel et al. 2000) diminuem com o atraso na época de controle das plantas daninhas e, mesmo que a cultura do milho seja considerada competitiva (Heemst 1986), pode ser severamente afetada pela interferência de plantas daninhas. Logo, deve-se prevenir a interferência, no período compreendido entre 10 e 50 dias após a emergência da cultura (Pitelli 1985, Sales 1991).

Dentre as espécies daninhas que infestam a cultura do milho, destaca-se a Brachiaria plantaginea (papuã ou capim-marmelada), como uma das gramíneas de maior ocorrência nas regiões Sul e Sudeste do Brasil (Kissmann \& Groth 1997). Esta é uma espécie muito competitiva, podendo levar a prejuízos consideráveis na produtividade e na qualidade de grãos (Fleck 1996, Kissmann \& Groth 1997), apresentando crescimento rápido e explorando eficientemente os recursos do meio, como água, luz e nutrientes. O efeito de $B$. plantaginea sobre a produtividade é negativo, afetando todos os componentes de rendimento de grãos do milho. Dependendo do componente do rendimento afetado pela presença desta espécie daninha e do período em que a competição acontece, pode ocorrer queda drástica na produtividade da cultura (Kozlowski 2002). Merotto Jr. et al. (1997), ao trabalharem com a interferência de $B$. plantaginea, relataram que a produtividade de grãos de milho foi reduzida em, aproximadamente, $90 \%$, quando nenhum controle foi realizado.

Os principais componentes do rendimento de grãos do milho são o número de espigas por unidade de área, o número de grãos por espiga e o peso de grãos (Mundstock 1999). O número e o tamanho de espigas de milho são, normalmente, os componentes mais afetados pela interferência das plantas daninhas (Mundstock \& Silva 1989). Rossi et al. (1996) relatam que a interferência de plantas daninhas reduz em $15 \%$ o tamanho de espigas de milho e em $28 \%$ o peso de grãos, resultando em $32 \%$ de perdas na produtividade de grãos.

A redução da competição das plantas daninhas, na cultura do milho, pode ser alcançada com o uso de práticas de controle realizadas antes ou após a emergência da cultura, ou dentro do período crítico de competição (Singh et al. 1996). Dentre as práticas de controle, destaca-se o uso de herbicidas, que podem ser aplicados em pré ou em pós-emergência da cultura ou das plantas daninhas. O uso de herbicidas para o controle de plantas daninhas tornou-se uma necessidade, em razão da escassez e do elevado custo da mão de obra, além da elevada eficiência com a execução desta operação, em tempo oportuno e de forma satisfatória (López-Ovejero et al. 2003).

Diversos são os herbicidas recomendados para o controle de plantas daninhas, na cultura de milho, sendo aplicados em condições de pré ou pós-emergência das plantas daninhas e da cultura (Silva \& Melhorança 1991).

Objetivou-se, com este trabalho, avaliar o controle de Brachiaria plantaginea, com herbicidas aplicados em pré e pós-emergência, e o efeito destes nos componentes de rendimento do híbrido de milho Pioneer 3063.

\section{MATERIAL E MÉTODOS}

O experimento foi conduzido a campo, de outubro de 2006 a fevereiro de 2007, no Centro Agropecuário da Palma (CAP) da Universidade Federal de Pelotas (UFPel), no município de Capão do Leão, RS ( $31^{\circ} 45^{\prime} 45^{\prime}$ 'S e $52^{\circ} 19^{\prime}$ '55'W), em sistema de cultivo convencional, com aração seguida de gradagem, em delineamento experimental de blocos casualizados, com quatro repetições. As unidades experimentais mediam $20 \mathrm{~m}^{2}(4 \mathrm{~m} \times 5 \mathrm{~m})$, sendo compostas por cinco linhas de plantio, com área útil de $10 \mathrm{~m}^{2}$ (2,5 m x $\left.4 \mathrm{~m}\right)$. Utilizou-se o híbrido triplo Pioneer-3063, de ciclo precoce (Embrapa 2006), semeado em espaçamento entre linhas de $0,80 \mathrm{~m}$, com densidade de 4,5 sementes $\mathrm{m}^{-1}$, obtendo-se população

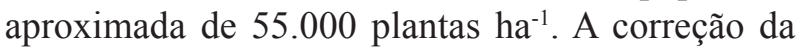
fertilidade do solo foi realizada de acordo com as recomendações técnicas, com $200 \mathrm{~kg} \mathrm{ha}^{-1}$ de adubo da fórmula 05-20-20 (N-P-K). No estádio fenológico de V6 a V8 da cultura, realizou-se a adubação nitrogenada, aplicando-se $115 \mathrm{~kg} \mathrm{ha}^{-1}$ de $\mathrm{N}$, na forma de ureia. Foi realizado levantamento populacional das 
plantas daninhas, com a contagem do número de indivíduos contidos em uma área de $0,25 \mathrm{~m}^{2}(0,5 \mathrm{~m} \mathrm{x}$ $0,5 \mathrm{~m})$. Nas parcelas referentes à testemunha sem o controle das plantas daninhas e nas que foram tratadas com os herbicidas pós-emergentes, a escolha da área foi feita de forma aleatória, obtendo-se a densidade média de 312 plantas por $\mathrm{m}^{2} \mathrm{de}$ B. plantaginea, sendo, estas, provenientes do banco de sementes do solo e exclusivas na área experimental.

Os tratamentos avaliados foram compostos pela aplicação do herbicida s-metolachlor $\left(1.620 \mathrm{~g} \mathrm{ha}^{-1}\right)$ e da mistura em tanque de atrazine + nicosulfuron $\left(1.250+28 \mathrm{~g} \mathrm{ha}^{-1}\right)$, aplicados em pré e pós-emergência, respectivamente, e mais uma testemunha capinada e outra infestada. A aplicação dos herbicidas foi realizada um dia após a emergência (DAE) da cultura, antes da emergência das plantas daninhas, para o herbicida em pré-emergência, e aos 14 DAE para a mistura aplicada em pós-emergência, com auxílio de pulverizador costal, pressurizado a $\mathrm{CO}_{2}$, com pressão constante de $254 \mathrm{kPa}$, equipado com barra de $2 \mathrm{~m}$, contendo quatro pontas de pulverização em leque (XR TeeJet ${ }^{\mathbb{R}}$ ), da série 110.02, espaçadas em $0,50 \mathrm{~m}$, possibilitando aplicação de $150 \mathrm{~L} \mathrm{ha}^{-1}$ de calda herbicida.

As avaliações de controle de $B$. plantaginea foram realizadas aos 7, 14, 21, 28, 35 e 42 dias após a aplicação dos tratamentos (DAT) e a última na pré-colheita. Todas as avaliações foram realizadas por escala visual, onde a nota zero $(0 \%)$ corresponde a nenhum controle da planta daninha e a nota cem $(100 \%)$ refere-se ao controle total da espécie daninha.

A produtividade de grãos de milho foi obtida aos 120 DAE, pela colheita manual das espigas da área útil de 2,5 $\mathrm{m} \mathrm{x} \mathrm{4,0} \mathrm{m.} \mathrm{Foram} \mathrm{consideradas} \mathrm{as} \mathrm{três}$ linhas centrais de cada parcela como área útil, sendo desconsideradas as duas linhas das extremidades.

Também, foram realizadas avaliações do comprimento de espigas $(\mathrm{cm})$, número de fileiras por espiga, número de grãos por fileira, número de grãos por espiga e produtividade de grãos $\left(\mathrm{kg} \mathrm{ha}^{-1}\right)$, corrigidos para $13 \%$ de umidade. Para isto, foram amostradas e analisadas 10 plantas de milho, tomadas ao acaso, em cada unidade experimental.

Os resultados obtidos foram submetidos a análise de variância $(\mathrm{p} \leq 0,05)$. Havendo significância estatística entre os tratamentos, foram realizadas análises adequadas. Os efeitos de épocas de controle de $B$. plantaginea foram avaliados por regressão, para os herbicidas em estudo, e, para os efeitos dos componentes do rendimento de grãos da cultura do milho, aplicou-se o teste de Duncan ( $\mathrm{p} \leq 0,05)$. Efetuou-se, ainda, análise multivariada, pelo método das variáveis canônicas, que consiste na transformação das variáveis originais em variáveis padronizadas e não correlacionadas com a característica de manter o princípio do processo de conglomeração, com base na distância de Mahalanobis (Mahalanobis 1936 apud Cruz 1990). Realizou-se, também, a análise de correlação linear de Pearson, para os componentes do rendimento de grãos do milho.

\section{RESULTADOS E DISCUSSÃO}

Os resultados mostram que o controle de B. plantaginea foi diferenciado, em função dos tratamentos herbicidas utilizados (Figura 1), com efeitos significativos nos componentes do rendimento de grãos da cultura (Tabela 1).

Para o herbicida s-metolachlor, aplicado (1 DAE do milho) em pré-emergência da planta daninha, detectou-se que o mesmo manteve controle satisfatório da espécie daninha, até os 14 DAE, ocorrendo novos fluxos de emergência de plantas daninhas, obtendo-se controle próximo a $20 \%$, aos 42 DAE, e nenhum controle na avaliação de pré-colheita (115 DAE). Isto influenciou, negativamente, a produtividade de grãos e, também, todos os componentes do rendimento de grãos da cultura, exceto o número de grãos por fileira (Figura 1 e Tabela 1). De acordo com Merotto Jr. et al. (2000), os herbicidas aplicados em pré-emergência podem

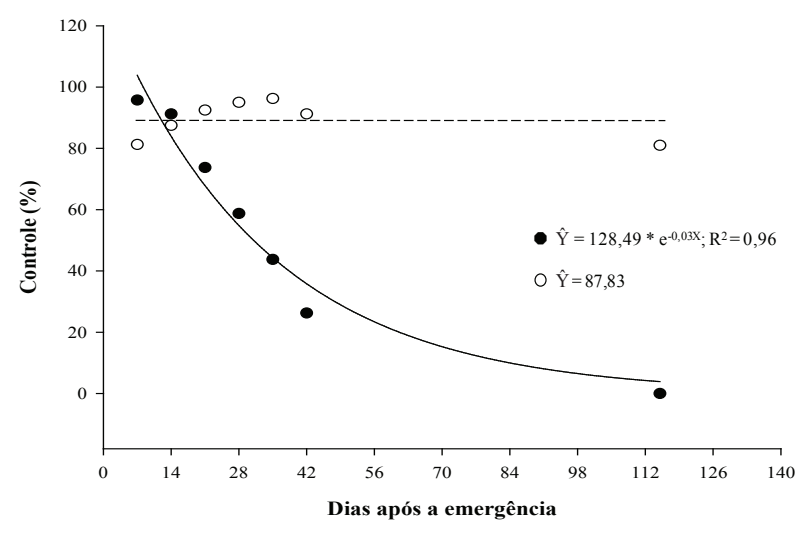

Figura 1. Controle de Brachiaria plantaginea (papuã), com o herbicida aplicado em pré (• s-metolachlor, $1.620 \mathrm{~g} \mathrm{ha}^{-1}$ ) e pós-emergência ( $\circ$ atrazine + nicosulfuron, $\left.1.250+28 \mathrm{~g} \mathrm{ha}^{-1}\right), 01$ ou 14 dias após a semeadura da cultura do milho. 
Tabela 1. Efeitos dos herbicidas aplicados em pré e pós-emergência sobre os componentes do rendimento de grãos da cultura do milho (Capão do Leão, RS, safra 2006/2007).

\begin{tabular}{|c|c|c|c|c|c|}
\hline Tratamentos & $\begin{array}{l}\text { Comprimento da } \\
\text { espiga }(\mathrm{cm})\end{array}$ & $\begin{array}{l}\mathrm{N}^{o} \text { de fileiras } \\
\text { espiga }^{-1}\end{array}$ & $\begin{array}{l}\mathrm{N}^{0} \text { de grãos } \\
\text { fileira }^{-1}\end{array}$ & $\begin{array}{l}\mathrm{N}^{\circ} \text { de grãos } \\
\text { espiga }^{-1}\end{array}$ & $\begin{array}{c}\text { Produtividade } \\
\mathrm{kg} \mathrm{ha}^{-1}\end{array}$ \\
\hline Testemunha infestada & $3,1 \mathrm{c}^{1}$ & $4,0 \mathrm{~b}$ & $5,1 \mathrm{c}$ & $40,9 \mathrm{c}$ & $50 \mathrm{c}$ \\
\hline S-metolachlor ${ }^{2}$ & $12,4 \mathrm{~b}$ & $12,5 \mathrm{a}$ & $20,2 \mathrm{~b}$ & $256,9 \mathrm{~b}$ & $511 \mathrm{~b}$ \\
\hline Atrazine + nicosulfuron ${ }^{3}$ & $15,5 \mathrm{a}$ & $13,5 \mathrm{a}$ & $27,7 \mathrm{a}$ & 373,9 a & $2.655 \mathrm{a}$ \\
\hline Testemunha capinada & $16,2 \mathrm{a}$ & $14,1 \mathrm{a}$ & $29,8 \mathrm{a}$ & $419,5 \mathrm{a}$ & $3.094 \mathrm{a}$ \\
\hline CV $(\%)$ & 14,9 & 23,3 & 16,9 & 18,0 & 28,0 \\
\hline
\end{tabular}

${ }^{1}$ Médias seguidas pela mesma letra minúscula, na coluna, não diferem entre si, pelo teste de Duncan ( $\left.\mathrm{p} \leq 0,05\right) .{ }^{2,3}$ Aplicados na dose de $1.620 \mathrm{~g}$ ha ${ }^{-1}$ e $1.250+28 \mathrm{~g}$ ha ${ }^{-1}$, respectivamente.

atuar como ferramenta para adoção de manejo integrado, no início do ciclo da cultura, que poderá ser complementado pelo rápido e intenso fechamento do dossel proporcionado por altas populações de plantas de milho (acima de 60.000 plantas ha $^{-1}$ ). Entretanto, esta vantagem competitiva não foi observada com o híbrido adotado.

Para a cultura do milho, existe necessidade, na maioria das situações, que os herbicidas mantenham período residual até os 50 DAE. Após este período, não há mais influência das plantas daninhas na interferência da produtividade da cultura, sendo denominado período crítico de competição (Sales 1991, Kozlowski 2002). Um dos motivos que pode ter colaborado para a baixa eficiência do herbicida s-metolachlor, neste estudo, pode ser a emergência de novas plantas de $B$. plantaginea, possibilitada pelo fato de a dose usada ser menor que a recomendada oficialmente, ocorrendo baixo efeito residual (Bedmar et al. 1999). De acordo com Kapusta et al. (1994), para herbicidas aplicados em pré-emergência, este é um dos fatores mais limitantes para se obter produtividades equivalentes àquelas obtidas com herbicidas que mantêm a cultura livre de plantas daninhas durante todo o ciclo, ou aos métodos mecânicos de controle com a adoção de capinas, em especial.

Deve-se ressaltar que os efeitos das plantas daninhas podem ser importantes mesmo antes da imposição da competição por água, nutrientes e luz (Merotto Jr. et al. 2000). Estes efeitos se devem às variações na qualidade da luz, que é refletida pelas folhas do dossel, e podem servir como importante sinal entre as plantas da comunidade (Schimitt \& Wulff 1993). Assim, o controle de plantas daninhas, desde a emergência da cultura, é importante para a redução dos seus efeitos sobre a produtividade de grãos da cultura (Bedmar et al. 1999). Desse modo, a tradicional indicação de que os efeitos das plantas daninhas somente passam a ocorrer algumas semanas após a emergência da cultura pode não ser válida para todas as situações (Holt 1995), principalmente no que se refere a altos níveis de exploração do ambiente e produtividade de grãos, bem como à capacidade competitiva da espécie infestante. Deve-se ressaltar que a $B$. plantaginea é considerada uma das espécies daninhas mais competitivas da cultura do milho (Merotto Jr. et al. 1997).

Destaca-se que o manejo integrado de plantas daninhas pode ser utilizado com o objetivo de racionalização de herbicidas e dos custos de produção (Merotto Jr. et al. 2000). Neste sentido, Merotto Jr. et al. (1997) destacam que as altas populações de milho reduzem em $50 \%$ os prejuízos causados por plantas daninhas. Os mesmos autores relatam, ainda, que a maior competição intraespecífica, proporcionada pelo aumento da população de plantas, intensifica-se somente nos estádios mais avançados de desenvolvimento da cultura, necessitando, assim, de uma complementação com outro método de controle, no início do ciclo.

Quanto à mistura herbicida utilizada (atrazine + nicosulfuron), observou-se que a mesma manteve controle intermediário de $B$. plantaginea superior a $80 \%$, em todo o período estudado, ou seja, dos $7 \mathrm{DAE}$ até a fase da pré-colheita, chegando a valores próximos aos $100 \%$ de controle, no período dos 28 aos 35 DAE (Figura 1). Deste modo, a cultura foi mantida no limpo, no período considerado como crítico para o controle de plantas daninhas (Sales 1991, Kozlowski 2002), e, assim, não houve interferência na produtividade e nos componentes da produtividade de grãos (Figura 1 e Tabela 1). Resultados similares aos obtidos com o uso de atrazine + nicosulfuron foram relatados por Merotto Jr. et al. (2000) e Rizzardi et al. (2008), para o controle de $B$. plantaginea, em estádios de até quatro afilhos, em condições de campo, na cultura do milho. Por porpiciar o controle de plantas daninhas que já emergiram (efeito do nicosulfuron) 
e das plantas que ainda não germinaram (efeito da atrazine), esta mistura tornou-se opção muito utilizada pelos produtores de milho. Além disso, atrazine é recomendada para o controle de plantas daninhas dicotiledôneas, em pré ou pós-emergência inicial, para a cultura do milho, enquanto o nicosulfuron é aplicado para o controle de mono e dicotiledôneas, em pós-emergência (Rizzardi et al. 2004).

Ao se observar que o período crítico para o controle de plantas daninhas, na cultura do milho, está compreendido entre 10 e $50 \mathrm{DAE}$, percebe-se que somente a mistura herbicida conseguiu atingir esta fase, enquanto o herbicida s-metolachlor proporcionou o controle de $B$. plantaginea no período considerado como anterior à interferência, que é de 10 a 15 DAE (Kozlowski 2002). Comparando o controle dos herbicidas aplicados em pré-emergência (s-metolachlor) e a mistura aplicada em pós-emergência (atrazine + nicosulfuron), observa-se que, ao optar pelo primeiro, obteve-se menor produtividade de milho, sendo esta somente superior à testemunha sem capina, enquanto, ao utilizar-se a mistura herbicida, manteve-se a cultura livre da infestação de $B$. plantaginea por tempo maior, refletindo no aumento significativo da produtividade de grãos, estatisticamente igual à testemunha mantida livre de infestação por todo o período (Tabela 1).

Os componentes do rendimento da cultura do milho foram afetados, significativamente, pelo uso dos herbicidas aplicados em pré ou pós-emergência, no controle de B. plantaginea (Tabela 1). O comprimento da espiga, número de grãos por fileira, número de grãos por espiga e, consequentemente, a produtividade de grãos foram significativamente maiores, ao utilizar-se a mistura herbicida (atrazine + nicosulfuron), em relação ao herbicida s-metolachlor. Estes resultados decorreram em função do controle da espécie daninha efetuado pela mistura herbicida, mantendo a cultura no limpo por todo o período crítico de competição (dos 10 aos $50 \mathrm{DAE}$ ), período, este, considerado fundamental para a cultura expressar toda a sua capacidade produtiva (Fancelli \& Dourado Neto 2000), sem que ocorra competição por água, nutrientes e luz. Ressalta-se, ainda, que a mistura herbicida proporcionou controle superior a $80 \%$, por todo o ciclo da cultura, o que não se verificou com o uso do s-metolachlor. Estes resultados corroboram os encontrados por Merotto Jr. et al. (2000) e Zagonel et al. (2000), ao avaliarem as mesmas variáveis, após a aplicação de herbicidas de pré e pós-emergência, na cultura do milho.
Ao analisar os componentes do rendimento, percebe-se que a mistura herbicida diferiu, significativamente, do uso de s-metolachlor e da testemunha sem capina, porém, igualou-se à testemunha capinada, para todas as variáveis analisadas, exceto para o número de fileiras por espigas, onde somente houve diferenciação para a testemunha infestada (Tabela 1). Não houve interferência de $B$. plantaginea, em função dos herbicidas utilizados, para o número de fileiras por espiga, pois, de acordo com Hanway (1963), a definição deste componente dá-se nos estádios V3 e V5, sendo que, nesta fase, independentemente do herbicida utilizado, a cultura foi mantida no limpo, não afetando o componente, exceto para a testemunha sem capina, que sofreu maior interferência.

Observa-se que o tratamento com uso da mistura atrazine + nicosulfuron, para o controle de B. plantaginea, apresentou superioridade de $20 \%$, $7 \%, 27 \%, 32 \%$ e $81 \%$, respectivamente, para comprimento da espiga, número de fileiras por espiga, número de grãos por fileira, número de grãos por espiga e produtividade de grãos (Tabela 1). $\mathrm{O}$ não controle desta espécie daninha, representado pela testemunha sem capina, ocasionou interferência em todos os componentes do rendimento da cultura, reduzindo em $5 ; 3,5 ; 6 ; 10$; e 62 vezes o comprimento da espiga, número de fileiras por espiga, número de grãos por fileiras, número de grãos por espiga e produtividade de grãos, respectivamente, quando comparado à cultura mantida no limpo, durante todo o ciclo (testemunha capinada).

A classificação da importância dos componentes do rendimento de grãos da cultura do milho, afetados pela interferência de $B$. plantaginea, foi efetuada pela técnica de variáveis canônicas, que consiste na transformação das variáveis originais em variáveis padronizadas e não correlacionadas, com a característica de manter o princípio do processo de conglomeração, com base na distância de Mahalanobis (Mahalanobis 1936 apud Cruz 1990). O novo conjunto de variáveis, em ordem de estimação, retém o máximo de informação, em termos de variação total, e explica melhor a variabilidade manifestada. Assim, pela análise multivariada dos dados, classificaram-se as variáveis em ordem de importância, de acordo com sua contribuição à distinção dos tratamentos. Devido ao alto valor de informação retida na variável canônica CAN1 (83,52\%) (Tabela 2), esta pode ser considerada suficiente para explicar a contribuição das variáveis originais analisadas, para os cinco tra- 
Tabela 2. Correlação entre as cinco variáveis originais, referentes aos componentes do rendimento de grãos da cultura do milho e de duas variáveis canônicas (CAN1 e CAN2), percentagem de informação retida e acumulada em CAN1 e CAN2 e variáveis discriminadas por ordem de importância (Capão do Leão, RS, safra 2006/2007).

\begin{tabular}{lcccc}
\hline \multicolumn{1}{c}{ Variável } & CAN1 & Ordem & CAN2 & Ordem \\
\hline Comprimento da espiga & 0,8763 & 1 & 0,8535 & 1 \\
Número de fileiras por espiga & $-0,4276$ & 5 & $-0,4257$ & 5 \\
Número de grãos por fileira & $-0,2214$ & 4 & $-0,2994$ & 4 \\
Número de grãos por espiga & 0,0137 & 2 & 0,0243 & 2 \\
Produtividade de grãos (kg ha $\left.{ }^{-1}\right)$ & 0,0004 & 3 & $-0,0027$ & 3 \\
\hline Informação retida (\%) & 83,52 & & 3,33 & \\
Informação acumulada (\%) & 83,52 & 86,75 \\
\hline
\end{tabular}

tamentos em cinco blocos. Para a segunda variável canônica (CAN2), a análise da Tabela 2 revela que a informação retida é de $3,33 \%$. Assim, as duas primeiras variáveis explicam $86,75 \%$ da variação total nos dados originais.

Em ordem decrescente de importância, a variável comprimento de espigas foi a primeira, seguida das variáveis número de fileiras por espiga, número de grãos por fileiras, número de grãos por espiga e produtividade de grãos (Tabela 2). Logo, o rendimento final de grãos da cultura está mais intimamente relacionado ao comprimento da espiga e ao número de fileiras por espiga. Entre todos os componentes do rendimento de grãos, o mais prejudicado pela interferência de $B$. plantaginea foi o comprimento da espiga $(\mathrm{cm})$. Isto pode decorrer da competição das plantas daninhas com a cultura, pelos elementos considerados essenciais ao crescimento das plantas e seus componentes de produção, como os nutrientes, água e luz (Radosevich et al. 1997), e, também, das diferentes técnicas de manejo adotadas com a cultura do milho (Santos et al. 2005). De acordo com Radosevich et al. (1997), o aumento da biomassa seca das plantas daninhas, nos estádios de desenvolvimento finais da cultura do milho, prejudicam a formação dos componentes que se desenvolvem no final do ciclo da cultura.

Entre todos os componentes do rendimento de grãos, o menos prejudicado pela interferência de B. plantaginea foi a produtividade final de grãos da cultura $\left(\mathrm{kg} \mathrm{ha}^{-1}\right)$ (Tabela 2$)$, já que a mesma é definida no período entre a emissão dos estigmas e a maturação fisiológica, pela quantidade de carboidratos acumulados no processo de fotossíntese (Daynard \& Kannenberg 1976). De acordo com Spader \& Vidal (2000), a interferência de plantas daninhas pode prejudicar a polinização, devido à defasagem no tempo entre a receptividade dos estigmas e a maturação dos grãos de pólen, reduzindo o número de óvulos fecundados, ou pode promover o abortamento dos óvulos fecundados, afetando o número de grãos formados. Outros autores relatam, ainda, que a semeadura de plantas de cobertura do solo, em consórcio com milho, a partir de 20 dias após a emergência da cultura, reduz o número de grãos por espiga e o peso de grãos do milho (Abdin et al. 1998). De acordo com estes autores, no período de florescimento e enchimento de grãos do milho, algumas espécies de plantas de cobertura apresentaram grande desenvolvimento vegetativo, afetando as plantas de milho.

Os efeitos da competição refletiram, significativamente, em todas as características estudadas, sendo que, para a variável produtividade de grãos de milho, ao se adotar algum controle de $B$. plantaginea, obteve-se incremento de produtividade 31 vezes maior, em relação à testemunha sem capina, para a qual nenhum controle foi realizado (Tabela 1). No entanto, observou-se, ainda, que a mistura herbicida aplicada em pós-emergência não diferiu, estatisticamente, da testemunha capinada, demonstrando-se, assim, que ocorreram danos mínimos de toxicidade à cultura e que o herbicida aplicado em pós-emergência foi, aproximadamente, cinco vezes superior ao s-metolachlor aplicado isoladamente, em pré-emergência, quanto à produtividade de grãos. Resultados semelhantes foram encontrados por Merotto Jr. et al. (2000), ao avaliarem herbicidas aplicados em pré-emergência e misturas herbicidas aplicadas em pós-emergência, para o controle de $B$. plantaginea, na cultura do milho, e a influência destes nos componentes do rendimento de grãos do milho.

Resultados semelhantes aos obtidos neste estudo foram observados por alguns pesquisadores que avaliaram a interferência de $B$. plantaginea na cultura do milho, bem como o controle desta espécie daninha, com o uso de herbicidas aplicados em pré ou em pós-emergência, onde foi observada interferência nos com- 
Tabela 3. Matriz de correlação linear de Pearson, entre as variáveis (Capão do Leão, RS, safra 2006/2007).

\begin{tabular}{lclc}
\hline Variáveis & Interação & Variáveis & Interação \\
\hline Produtividade de grãos x grãos por espiga & $0,88 * *$ & Grão por espiga x fileira por espiga & $0,91 * *$ \\
Produtividade de grãos x grãos por fileira & $0,84 * *$ & Grão por espiga x comprimento por espiga & $0,96 * *$ \\
Produtividade de grãos x fileira por espiga & $0,67 * *$ & Grãos por fileira x fileira por espiga & $0,93 * *$ \\
Produtividade de grãos x comprimento de espiga & $0,80 * *$ & Grãos por fileira x comprimento de espiga & $0,98 * *$ \\
Grãos por espiga x grãos por fileira & $0,98 * *$ & Fileira por espiga x comprimento de espiga & $0,97 * *$ \\
\hline
\end{tabular}

** Significativo a $1 \%$, pela análise de correlação linear de Pearson.

ponentes da produtividade da cultura, sendo definida a melhor época para a realização do controle das plantas daninhas (Merotto Jr. et al. 2000, Zagonel et al. 2000, López-Ovejero et al. 2003) e, também, a determinação do período crítico para o controle de plantas daninhas na cultura do milho (Kozlowski 2002).

Todas as correlações efetuadas entre os componentes do rendimento foram significativas neste estudo (Tabela 3). A interferência de $B$. plantaginea nos componentes afetou a produtividade da cultura e a análise de correlação indicou que $98 \%$ da variação da produtividade de grãos foi determinada pelo número de grãos por espiga $\mathrm{x}$ número de grãos por fileira e número de grãos por fileira x comprimento da espiga, enquanto $96 \%$ e $97 \%$ foram explicados pelo número de grãos por espiga $\mathrm{x}$ comprimento da espiga e número de fileiras x comprimento da espiga, respectivamente.

Obteve-se a menor correlação para a produtividade de grãos $\mathrm{x}$ número de fileiras de grãos com $67 \%$ da explicação da interferência de B. plantaginea, exatamente a variável em que não houve diferenciação entre a aplicação de s-metolachlor e a mistura de atrazine + nicosulfuron com a testemunha capinada, fenômeno já explicado anteriormente. De acordo com Mundstock \& Silva (1989), o número de grãos por espiga representa um dos principais componentes do rendimento da cultura do milho.

\section{CONCLUSÕES}

1. O uso do herbicida s-metolachlor, aplicado em pré-emergência, é uma alternativa para se manter a cultura do milho livre da competição de Brachiaria plantaginea, até 20 dias após a emergência.

2. A mistura dos herbicidas atrazine + nicosulfuron, aplicada em pós-emergência, é uma alternativa eficiente para o controle de Brachiaria plantaginea, mantendo a cultura do milho no limpo, durante todo o ciclo.

\section{REFERÊNCIAS}

ABDIN, O. et al. Yield and yield components of corn interseeded with cover crops. Agronomy Journal, Madison, v. 90, n. 1, p. 63-68, 1998.

ALMEIDA, F. S. Eficácia de herbicidas pós-emergentes no controle de plantas daninhas na cultura do milho. In: INSTITUTO AGRONÔMICO DO PARANÁ (Iapar). Plantio direto no Estado do Paraná. Londrina: Iapar, 1981. p. 101-144.

BEDMAR, F.; MANETTI, B.; MONTERUBBIANESI, G. Determination of the critical period of weed control in corn using a thermal basis. Pesquisa Agropecuária Brasileira, Brasília, DF, v. 34, n. 2, p. 187-183, 1999.

COMPANHIA NACIONAL DE ABASTECIMENTO (Conab). Indicadores da agropecuária. 2007. Disponível em: <http://www.conab.gov.br>. Acesso em: 27 jul. 2008.

CRUZ, C. D. Aplicações de algumas técnicas multivariadas no melhoramento de plantas. Piracicaba: ESALQ, 1990.

DAYNARD, T. B.; KANNENBERG, L.W. Relationship between length of actual and effective filling periods and the grain yield of corn. Canadian Journal of Political Science, Montreal, v. 56, n. 2, p. 237-242, 1976.

EMPRESA BRASILEIRA DE PESQUISA AGROPECUÁRIA (Embrapa). Indicações técnicas para o cultivo de milho e de sorgo no Rio Grande do Sul. In: REUNIÃO TÉCNICA ANUAL DE MILHO, 51., 2006, Passo Fundo. Anais... Passo Fundo: Embrapa Trigo, 2006. 1 CD-ROM.

FANCELLI, L. A.; DOURADO NETO, D. Manejo de plantas daninhas. In: FANCELLI, L. A.; DOURADO NETO, D. (Eds.). Produção de milho. Guaíba: Agropecuária, 2000. p. 183-215.

FLECK, N. G. Interferência de papuã (Brachiaria plantaginea) com soja e ganho de produtividade obtido através do seu controle. Pesquisa Agropecuária Gaúcha, Porto Alegre, v. 2, n. 1, p. 63-68, 1996.

HANWAY, J. J. Growth stages of corn (Zea mays). Agronony Journal, Madison, v. 55, n. 5, p. 487-491, 1963. 
HEEMST, G. H. The influence of weed competition on crop yield. Systems Agriculture, Essex, v. 18, n. 2, p. 8183, 1986.

HOLT, J. Plant responses to light: a potential tool for weed management. Weed Science, Lawrence, v. 43, n. 4, p. 464-482, 1995.

KAPUSTA, G. et al. Effect of nicosulfuron rate, adjuvant, and weed size on annual weed control in corn (Zea mays). Weed Technology, Champaign, v. 8, n. 4, p. 696-702, 1994.

KARAM, D.; MELHORANÇA, A. L. Cultivo do milho e plantas daninhas. Sete Lagoas: Embrapa-CNPMS, 2002. (Comunicado técnico, 58).

KARAM, D.; CRUZ, M. B. Sem concorrentes: manter o terreno limpo, sem invasoras é o primeiro passo para garantir o desenvolvimento. Cultivar Grandes Culturas, Pelotas, v. 6, n. 1, p. 1-10, 2004.

KISSMANN, K. G.; GROTH, D. Plantas infestantes e nocivas. 2. ed. São Paulo: BASF, 1997.

KOZLOWSKI, L. A. Período crítico de interferência das plantas daninhas na cultura do milho baseado na fenologia da cultura. Planta Daninha, Viçosa, v. 20, n. 3, p. 365372, 2002.

LÓPEZ-OVEJERO, R. F. et al. Seletividade de herbicidas para a cultura de milho (Zea mays) aplicados em diferentes estádios fenológicos da cultura. Planta Daninha, Viçosa, v. 21, n. 3, p. 413-419, 2003.

LORENZI, H. Manual de identificação e controle de plantas daninhas: plantio direto e convencional. 4. ed. Nova Odessa: Plantarum, 1994.

MEROTTO JR., A.; ALMEIDA, M. L.; FUNCHS, O. Aumento do rendimento de grãos de milho através do aumento da população de plantas. Ciência Rural, Santa Maria, v. 27, n. 4, p. 549-554, 1997.

MEROTTO JR., A. et al. Redução da interferência de Brachiaria plantaginea (Link) Hitch. em milho através de capinas e aplicação de herbicidas em diferentes épocas. Planta Daninha, Viçosa, v. 18, n. 3, p. 474-477, 2000.

MUNDSTOCK, C. M. Bases fisiológicas para aumentar o rendimento do milho no Sul do Brasil. In: REUNIÃO TÉCNICA CATARINENSE DE MILHO E FEIJÃO, 2., 1999, Lages. Resumos... Lages: Udesc/Epagri, 1999. p. 31-38.

MUNDSTOCK, C. M.; SILVA, P. R. F. Manejo da cultura do milho. Porto Alegre: UFRGS, 1989.

PITELLI, R. A. Interferências de plantas daninhas em culturas agrícolas. Informe Agropecuário, Belo Horizonte, v. 11, n. 1, p. 16-27, 1985.
RADOSEVICH, S.; HOLT, J.; GHERSA, C. Weed ecology: implications for management. 2. ed. New York: Wiley, 1997.

RIZZARDI, M. A.; KARAM, D.; CRUZ, M. B. Manejo e controle de plantas daninhas em milho e sorgo. In: VARGAS, L.; ROMAN, E. S. Manual de manejo e controle de plantas daninhas. Bento Gonçalves: Embrapa Uva e Vinho, 2004. p. 571-594.

RIZZARDI, M. A. et al. Controle de plantas daninhas em milho em função de épocas de aplicação de nitrogênio. Planta Daninha, Viçosa, v. 26, n. 1, p. 113-121, 2008.

ROSSI, I. H. et al. Interferência das plantas daninhas sobre algumas características agronômicas e a produtividade de sete cultivares de milho. Planta Daninha, Viçosa, v. 14, n. 2, p. 134-148, 1996.

SALES, J. L. Determinação dos periodos de interferência e integração de práticas culturais com herbicidas no controle de plantas daninhas na cultura do milho (Zea mays L.). 1991. 151 f. Tese (Doutorado em Fitotecnia)Escola Superior de Agricultura Luiz de Queiroz, Universidade de São Paulo, Piracicaba, 1991.

SANTOS, I. C. et al. Comportamento de cultivares de milho conduzidos organicamente e correlações entre características das espigas colhidas no estádio verde. Revista Brasileira de Milho e Sorgo, Sete Lagoas, v. 4, n. 1, p. 45-53, 2005.

SCHIMITT, J.; WULFF, R. D. Light spectral quality, phytochrome and plant competition. Trends in Ecology and Evolution, Victoria, v. 8, n. 1, p. 47-51, 1993.

SILVA, A. A.; MELHORANÇA, A. L. Controle de plantas daninhas na cultura do milho. In: EMPRESA BRASILEIRA DE PESQUISAAGROPECUÁRIA. Milho: informações técnicas. Dourados: Embrapa, 1991. p. 114127. (Circular técnica, 20).

SINGH, M. et al. Estimation of critical period of weed control. Weed Science, Lawrence, v. 44, n. 2, p. 273-283, 1996.

SPADER, V.; VIDAL, R. A. Interferência de Brachiaria plantaginea sobre características agronômicas, componentes do rendimento e produtividade de grãos do milho. Planta Daninha, Viçosa, v. 18, n. 3, p. 465-470, 2000.

ZAGONEL, J.; VENÂNCIO, W. S.; KUNZ, R. P. Efeito de métodos e épocas de controle das plantas daninhas na cultura do milho. Planta Daninha, Viçosa, v. 18, n. 1, p. 143-150, 2000. 